\title{
əCombined Dynamical and Statistical Downscaling for High-Resolution Projections of Multiple Climate Variables in the Beijing-Tianjin-Hebei Region of China
}

\author{
Zhenyu Han, Ying Shi, Jia Wu, AND Ying Xu \\ National Climate Center, China Meteorological Administration, Beijing, China \\ BOTAO ZHOU \\ Collaborative Innovation Center on Forecast and Evaluation of Meteorological Disasters/Key Laboratory of Meteorological \\ Disaster, Ministry of Education, Nanjing University of Information Science and Technology, Nanjing, China
}

(Manuscript received 26 February 2019, in final form 15 July 2019)

\begin{abstract}
High-resolution combined dynamical and statistical downscaling for multivariables (HDM) was performed in the Beijing-Tianjin-Hebei (BTH) region by using observations from China Meteorological Administration Land Data Assimilation System (CLDAS), a regional climate model (RCM), and quantile mapping. This resulted in the production of a daily product with six variables (daily mean, maximum, and minimum temperature; precipitation; relative humidity; and wind speed), five ensemble members, a multidecadal time span (1980-2099), and a high resolution $(6.25 \mathrm{~km})$ for climate change projections under the RCP 4.5 scenario. The evaluation showed that the HDM output could reproduce well the mean states of all variables and most extreme indices except the consecutive dry and wet days. The biases in the magnitude of interannual variability in HDM were mostly inherited from the RCM. By using the HDM, future projection over BTH was conducted. The results indicated that the annual mean temperature and precipitation as well as extreme heat and heavy precipitation events will increase over most regions. The warming magnitudes over the mountainous and coastal area at the northern BTH and the wetting magnitudes over the Daqinghe River basin (DRB) within BTH will be relatively stronger. The increases in extreme heat events will be much larger in the plain area. More than one-half of regions with the large extreme precipitation increase will be located within DRB. Both the number of models with the same sign of change and the ensemble standard deviation were used to estimate the projection uncertainty. The projected changes and uncertainties over DRB and subregions and Xiong'an city within the basin for each season are also discussed.
\end{abstract}

\section{Introduction}

The Beijing-Tianjin-Hebei (BTH, including the Beijing municipality, Tianjin municipality, and Hebei Province) region located in North China is a political, economical, and cultural center of China. Designated as a New Area city, Xiong'an sits at the center of the BTH (Fig. 1a). In this region, there is increasing evidence of a changing climate in the form of more frequent and more intense extreme events (Zhou et al. 2013; Jiang et al. 2018; Y. Zhang et al. 2017). Because of the serious consequences

¿ Denotes content that is immediately available upon publication as open access.

Corresponding author: Botao Zhou, zhoubt@nuist.edu.cn stemming from variations of the mean climate and increases in extremes in a future driven by intensifying anthropogenic greenhouse effects, the projected changes have been studied extensively. Presently, reliable projections of the mean climate and extremes are needed for better understanding of the consequences of global warming over this region (Fu et al. 2009; Shi et al. 2010; Liu et al. 2013; Kang and Eltahir 2018).

A global climate model (GCM) is the most essential tool for projecting the future climate under different emission scenarios. However, GCMs still show major deficiencies when it comes to representing small-scale processes that may influence the regional climate. Therefore, in order to generate climate information at a regional or local scale, it is necessary to apply downscaling techniques (Giorgi et al. 2009). The downscaled regional or local 

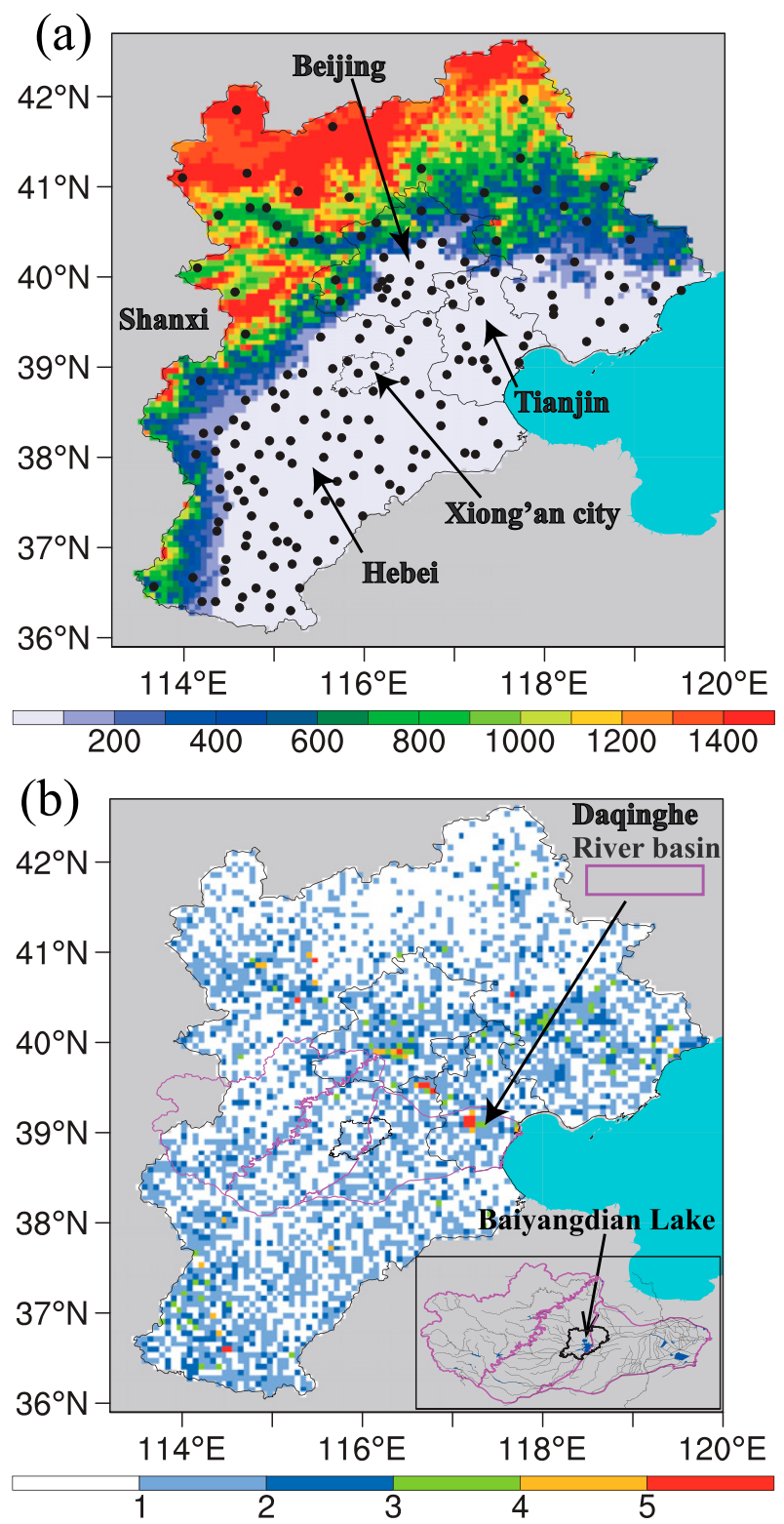

FIG. 1. Area of study: (a) Topographic map (m) and locations of the national meteorological stations used in the evaluation and (b) station density (number of stations over the single $0.0625^{\circ} \times 0.0625^{\circ}$ grid) of all national and regional meteorological stations. The pink lines in (b) show the location of the Daqinghe River basin and three subregions in this basin.

climate information is also very important to quantitative impact assessment and risk analysis, such as water resources and water-related disasters (IPCC 2015). To obtain high-resolution projections, two approaches are commonly used, namely, dynamical downscaling using a regional climate model (RCM) and statistical downscaling (SD).

RCMs can be the best dynamical downscaling tools for obtaining long-term climate change data at a regional scale till now, which have been applied in a number of studies on the East Asia climate and exhibit reasonable performances. Besides the stand-alone RCM, RCMs coupled with an ocean model have also been developed to further improve the performance (e.g., Zou et al. 2016; Zou and Zhou 2017; Gao et al. 2017; Hui et al. 2018). However, this approach is still associated with some limitations when simulating climatology on a daily time scale and climate variability (Casanueva et al. 2016; Zou et al. 2016; Bucchignani et al. 2017; Gao and Giorgi 2017), indicating that systematic bias cannot be avoided when applying current state-of-the-art RCM. Meanwhile, the available resolutions of $25-50 \mathrm{~km}$ are still coarser than what is needed for impact models on regional or local scales; convection permitting modeling can be a good choice (P. Li et al. 2019), however, use of higher resolutions (higher than $10 \mathrm{~km}$ ) and multimember dynamical downscaling is very costly.

In contrast, the computational costs of SD are much lower. This characteristic makes SD easy to apply to a large number of projection simulations for the generation of high-resolution regional climate data. There are a variety of SD methods, which can be categorized into subgroups, for example, perfect prognosis (PP), model output statistics (MOS), and stochastic weather generators, using the classification of Maraun et al. (2010). A MOS method-quantile mapping (QM) - is one of the most popular SD methods; it can be conducted on the basis of either theoretical distributions or empirical distribution (Boé et al. 2007; Piani et al. 2010; Gudmundsson et al.2012; Cannon et al. 2015). The QM method has been applied widely over China and is proven to be effective (e.g., Wang and Chen 2014; Fang et al. 2015; Chen et al. 2016; Reder et al. 2016; Tong et al. 2017; Han et al. 2018; Li et al. 2018).

To obtain a high-resolution (higher than $10 \mathrm{~km}$ ) and multimember downscaling dataset for future climate projections in the BTH region, a system that uses both dynamical and statistical downscaling techniques was devised in this paper. This system combines the merits of the above two downscaling methods, and it uses multiRCMs to downscale the GCM projection simulations at the $25-\mathrm{km}$ resolution, and then QM is used to further downscale the RCM simulations at the $6.25-\mathrm{km}$ resolution. A similar joint strategy has been used by other researchers (Wang et al. 2015; Kim et al. 2016; X. Zhou et al. 2018), but such an approach has not been applied and evaluated in the BTH region.

This paper is organized as follows: The data and evaluation methods are described in section 2. The downscaling system is introduced in section 3 . Evaluations of the downscaled product and an application example involving climate projections derived by using this product 
are presented in section 4 and section 5 , respectively. The main contents of this work are summarized in section 6 .

\section{Data and methods}

a. Data

\section{1) CLDAS}

Version 2.0 of the China Meteorological Administration Land Data Assimilation System (CLDAS) dataset developed by the China Meteorological Administration (CMA) was used as the observation data for statistical downscaling in this study (Shi et al. 2011, 2014). The spatial coverage is $60^{\circ}-160^{\circ} \mathrm{E}$ and $0^{\circ}-65^{\circ} \mathrm{N}$, and the temporal coverage is from 2008 to 2017 . This dataset provides a variety of daily and hourly land surface forcing data on a $0.0625^{\circ} \times 0.0625^{\circ}$ grid, including precipitation (PR), temperature [daily mean (TA), daily maximum (TX), and daily minimum (TN)], wind speed (WS), specific humidity $(\mathrm{SH})$, shortwave radiation ( $\mathrm{SW}$ ), and surface pressure (PS), as well as soil status variables. The relative humidity (RH), which is used for downscaling in this study, can be derived by using these variables. Note that $\mathrm{RH}$ is first derived and then statistically downscaled as suggested by Grenier (2018) but cannot be derived using downscaled PS, TA, and SH, because the latter strategy might cause some problems related to physical consistency (e.g., downscaled SH could exceed its corresponding saturation value determined by TA and PS).

The PR data merge observations made at 30000-40000 automatic stations in China together with the satellitebased Climate Prediction Center morphing technique (CMORPH) analyses through the use of a probability density function (PDF) and optimal interpolation algorithm (Shen et al. 2014). The TA, TX, TN, SH, WS, and PS data are produced by using Space-Time Multiscale Analysis System (STMAS; Xie et al. 2011) in combination with European Center for MediumRange Weather Forecasts (ECMWF) analysis data and station observations. This dataset has been well evaluated and used as land surface forcing data by previous studies [Yang et al. (2017), Meng and Wang (2017), and other papers within the Special Issue of "Application of the China Meteorological Assimilation Driving Datasets for the SWAT Model (CMADS) in East Asia"]. Readers can go to the Internet for more information about the CLDAS data (http://data.cma.cn/ data/cdcdetail/dataCode/NAFP_CLDAS2.0_NRT.html).

The spatial resolution of the CLDAS data is 5.09$6.95 \mathrm{~km}$ for different locations in BTH, and it is about $6.25 \mathrm{~km}$ on average. There are in total about $2000-3400$ stations located throughout the BTH region that provide observational data during 2008-17, and these stations are managed by the national or provincial meteorological bureaus. Figures $1 \mathrm{a}$ and $1 \mathrm{~b}$ show maps of the topography and station density at a $6.25-\mathrm{km}$ horizontal resolution over the BTH region. The density of observation stations is generally higher over the plain regions and lower over the mountainous regions. The high density of stations (0-2 stations per $10 \mathrm{~km}^{2}$ ) provides favorable conditions for obtaining quality, high-resolution grid data over the BTH region. Considering the actual station density, other published datasets with resolutions as high as $1 \mathrm{~km}$ produced by the interpolation approach based on only a portion of the national stations (there are no more than 175 national stations during $2008-17$ over the whole BTH region) were not considered (e.g., T. Li et al. 2014); presumably, the horizontal resolution of this study's observational-based dataset-CLDASis the highest among publicly available data.

\section{2) $\mathrm{RCM}$}

The RCM data were based on a $25-\mathrm{km}$-resolution dataset obtained dynamical downscaling by using the RCM of RegCM4.4. The RCM domain was the same as the Phase II East Asia domain of the international Coordinated Regional Climate Downscaling Experiment (CORDEX; Giorgi et al. 2009), which encompasses continental China in its entirety and adjacent areas. This model was driven by the boundary conditions from the historical (1979-2005) and representative concentration pathway 4.5 (RCP4.5; 2006-99) runs of five CMIP5 global models, that is, CSIROMk3-6-0, EC-EARTH, HadGEM2-ES, MPI-ESMMR, and NorESM1-M (acronym definitions can be found at https:///www.ametsoc.org/PubsAcronymList). The first year was excluded from the analysis as model spinup. The historical simulation denotes the past climate, and the RCP4.5 represents the medium-low radiative forcing scenario with radiative forcing peaking at $4.5 \mathrm{~W} \mathrm{~m}^{-2}$ by 2100 (Taylor et al. 2012). Readers can obtain more information about the five CMIP5 models and the scenario online (https://pcmdi.llnl.gov/mips/cmip5/). A subset of this ensemble experiment has been evaluated and used by different climate projection studies (Han et al. 2017; D. Zhang et al. 2017; Gao et al. 2018; Shi et al. 2018a,b; B. Zhou et al. 2018).

Note that to construct the transfer function during the statistical downscaling, only 10 years from 2008 to 2017 can be used as the calibration period, which is limited by the temporal coverage of CLDAS data. Meanwhile, because historical simulation outputs were not available for the period after 2005, the RCM data during the calibration period were derived from future projection simulations based on the RCP4.5. Because the main purpose of this study was to develop the methodology 
for a combined dynamical and statistical downscaling approach, in the evaluation section only data downscaled from a single GCM (HadGEM2-ES) were used; the evaluations on $6.25-\mathrm{km}$-resolution downscaling data based on other GCM were similar. Then, the average of the five simulations with equal weights was taken as the ensemble mean for the climate change projection study.

\section{3) StATion DATA}

Figure 1a shows the locations of 175 national meteorological stations in the BTH region. There were no missing records at these stations for daily TA, TX, TN, PR, and RH data from 2008 to 2017, and there were only 53 missing records for daily WS data. In contrast, the regional meteorological stations managed by the provincial meteorological bureaus suffered from more data series integrity issues. So, in this study the data collected at the national stations from 2008 to 2017 were chosen for the evaluation of the proposed high-resolution combined dynamical and statistical downscaling for multivariables (HDM) approach. The HDM outputs were interpolated by using the nearest grid to the locations of the 175 stations to facilitate the comparison.

\section{4) $\mathrm{CN} 05.1$}

The observational dataset of $\mathrm{CN} 05.1$ at a resolution of $0.25^{\circ} \times 0.25^{\circ}(\mathrm{Wu}$ and Gao 2013) was employed to validate the RCM simulation with a similar resolution$25 \mathrm{~km}$. CN05.1 is an augmentation of CN05 (Xu et al. 2009) and comprises multiple variables (TA, TX, TN, $\mathrm{PR}$, WS, RH, and evaporation). The RCM outputs were interpolated bilinearly to the $\mathrm{CN} 05.1$ grid to facilitate the comparison.

\section{b. Evaluation method}

The evaluation of variables in downscaled data made use of three standard metrics, namely, the bias, the spatial correlation coefficient (COR), and the root-mean-square error (RMSE), while focus was placed on the long-term mean, interannual variability, and climate extremes. Taylor diagrams (Taylor 2001) were also used to describe the correspondence between the downscaled data and reference data; these diagrams provide a concise statistical summary of how well different patterns match each other in terms of the COR, RMSE, and ratio of variances.

Eight extreme temperature and eight precipitation indices were chosen to illustrate the HDM performance in simulating the climate extremes, and these indices were based on the definitions of the Expert Team on Climate Change Detection and Indices (ETCCDI; Karl et al. 1999; Zhang et al. 2011). The temperature-related indices used included frost days (FD), icing days (ID), summer days (SU), tropical nights (TR), the annual maximum value of TX (TXx), the annual maximum value of TN (TNX), the annual minimum value of TX (TXn), and the annual minimum value of TN (TNn). The precipitation-related indices used included the maximum 1-day precipitation (Rx1day), maximum consecutive 5-day precipitation (Rx5day), simple precipitation intensity index (SDII), annual count of days when PR $\geq$ $1 \mathrm{~mm}$ (R1), annual count of days when PR $\geq 10 \mathrm{~mm}$ (R10), annual count of days when $P R \geq 20 \mathrm{~mm}$ (R20), annual maximum number of consecutive days with $\mathrm{PR}<$ $1 \mathrm{~mm}$ (CDD), and annual maximum number of consecutive days with $P R \geq 1 \mathrm{~mm}$ (CWD).

\section{Downscaling system}

Figure 2 shows a schematic diagram of the downscaling system, which consists of dynamical downscaling (using RCM nested with a GCM) and statistical downscaling (using high-resolution observations from CLDAS, bias correction on an annual cycle, and QM correction). The product of this system-daily HDM data-consists of multivariables, multimembers, a multidecadal time span (1980-2099), and high-resolution information $(6.25 \mathrm{~km})$, and it can be used for climate change projections.

\section{a. Bias correction on an annual cycle}

As shown in Fig. 3a, although the seasonal cycle was generally captured by the RCM, the daily series did not match the observation data well for much of year. Specifically, the RCM overestimated the daily precipitation in each season. Especially for the single peak value observed in July, the RCM simulated two overestimated peaks, which also occurred half a month earlier than the observed one.

Following the strategy of Kim et al. (2016), in the first step, the CLDAS was used to provide the climatological annual cycle at a daily time scale with a $6.25-\mathrm{km}$ horizontal resolution. Meanwhile, the RCM was used to provide anomalies at a daily time scale, which were interpolated at the $6.25-\mathrm{km}$ grid. By using two datasets, it was possible to combine the observation-based annual cycle with the model-based anomalies to obtain an intermediate dataset (HDM_interim). This procedure can be classified as the delta method, which is the simplest SD method, and it has been widely used in climate projection studies (e.g., Shi et al. 2010). The intermediate dataset can improve the annual cycle bias at a daily time scale exhibited by RCMs and thereby provides superior input data for QM.

\section{b. $Q M$}

Figure $3 \mathrm{~b}$ shows the frequencies of different precipitation intensity for the RCM, HDM_interim, CN05.1, 


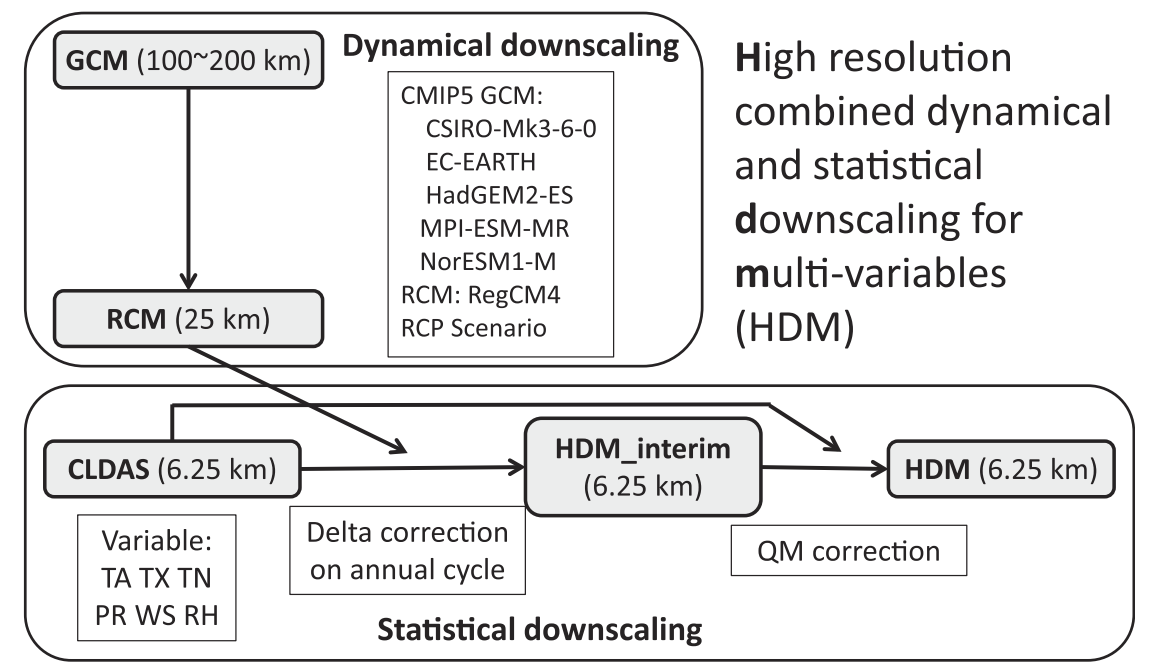

FIG. 2. Schematic diagram of the downscaling system based on CLDAS, RCM projection data, and quantile mapping.

and CLDAS. Compared to both observation datasets, the RCM significantly underestimated the dry days (intensity $<1 \mathrm{~mm} \mathrm{day}^{-1}$ ), while it overestimated the occurrence probability of precipitation with an intensity $\geq 1 \mathrm{~mm}$ day $^{-1}$. After the first step, the bias in the frequency distribution was partly corrected, especially for the dry days and heavy precipitation days (intensity $>$ $70 \mathrm{~mm} \mathrm{day}^{-1}$ ). However, the distribution over about 10 $70 \mathrm{~mm} \mathrm{day}^{-1}$ still did not match the observation data.

In the second step, QM based on empirical distribution was used to correct the systematic bias between the intermediate data and observations. Here, QM is actually the quantile delta mapping (QDM) described in Cannon et al. (2015), which is similar to the equidistant QM used in Li et al. (2010) and equiratio QM used in Wang and Chen (2014). In this method, the future change signal in quantiles simulated by a climate model is preserved. The additive form of QM (similar to equidistant $\mathrm{QM}$ ) is used for a variable that is measured on an interval scale, such as temperature, while the multiplicative form of QM (similar to equiratio QM) is used for a variable that is measured on a ratio scale, such as precipitation, relative humidity, and wind speed. Depending on the formulation, they will either preserve relative or absolute changes-the "deltas"-in quantiles simulated by the RCM. Take the QDM correction on temperature as an example, the bias-corrected future projection $\hat{x}_{m, p}(t)$ for model projected variable $x_{m, p}(t)$ at time $t$ is

$$
\begin{aligned}
\hat{x}_{m, p}(t)= & x_{m, p}(t)-F_{m, h}^{-1}\left\{F_{m, p}^{(t)}\left[x_{m, p}(t)\right]\right\} \\
& +F_{o, h}^{-1}\left\{F_{m, p}^{(t)}\left[x_{m, p}(t)\right]\right\},
\end{aligned}
$$

where the subscripts $o, m, h$, and $p$ indicate observation, model data, historical period, and projected period, respectively. The $F()$ are cumulative distribution functions (CDFs), while $F^{-1}()$ are inverse CDFs. The first two terms in the right-hand side are associated with the change in quantiles between the historical and future periods, and the third term is associated with the QM correction using the observed CDF. For comparison, the bias-corrected future projection $\hat{x}_{m, p}(t)$ using the conventional QM method is also shown as following:

$$
\hat{x}_{m, p}(t)=F_{o, h}^{-1}\left\{F_{m, h}^{(t)}\left[x_{m, p}(t)\right]\right\} .
$$

By using this QDM method, the projected future changes in the RCM were preserved. For more details on the QDM method, please refer to Cannon et al. (2015).

For the conventional QM method [Eq. (2)], because it cannot guarantee that the finite length calibration period used to derive transfer functions covers the entire spectrum of the variable of interest, for the future period the extrapolation of the transfer function beyond the observed range is required (Ehret et al. 2012). The results from Reiter et al. (2016) show that a small reduction in the length of the calibration period can result in a significant decrease of the QM bias-correction performance. However, with the QDM method, it can be seen from the two last terms in the right-hand side of Eq. (1) that the cumulative frequencies are calculated by $F_{m, p}^{(t)}\left[x_{m, p}(t)\right]$, which is based only on the future period, so the extrapolation is not needed, then the effect of the calibration period length mentioned above can be ignored. Besides, the QDM algorithms were applied to pooled daily data falling within sliding 3-month windows centered on the month of interest, which can enlarge statistics for building the CDFs. Then, the observations 

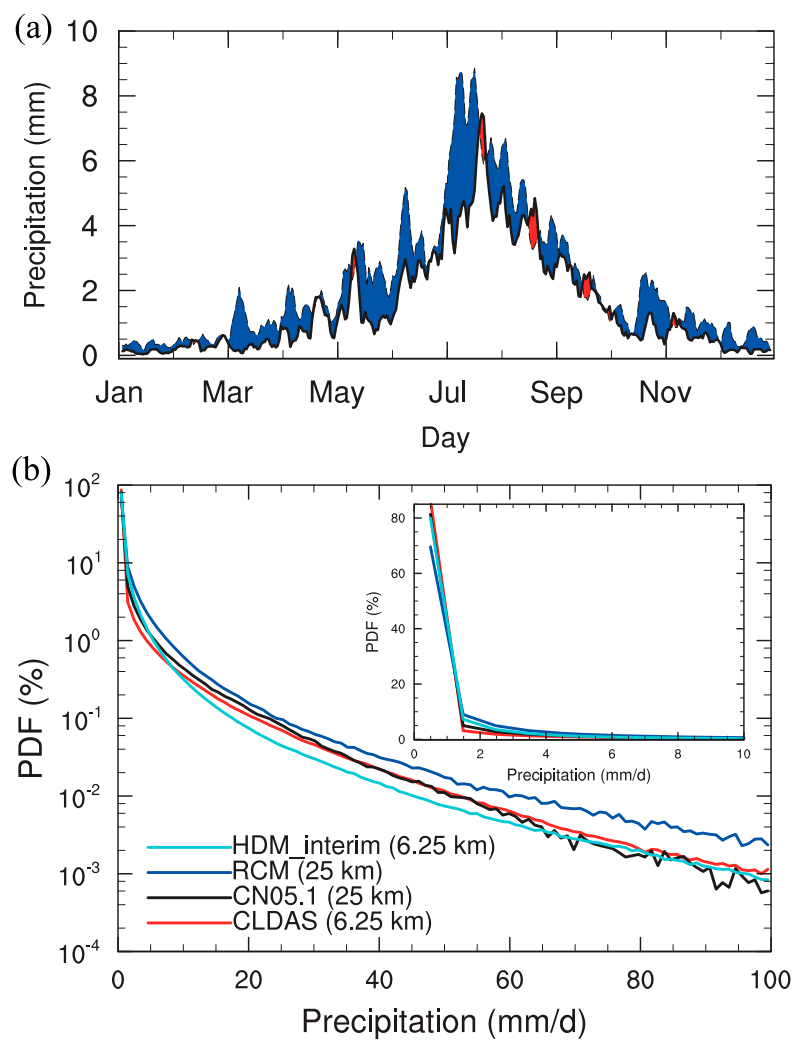

FIG. 3. (a) Time series of simulation biases in precipitation (shading) for the RCM compared with the observed climatological annual cycle (5-day moving average) using the CN05.1 (solid black line) averaged over the BTH region during 2008-17. (b) Probability density function distributions of the daily precipitation intensity $\left(\mathrm{mm} \mathrm{day}^{-1}\right.$ ) over the BTH region from the observation datasets (CN05.1 and CLDAS), RCM, and intermediate downscaling data (HDM_interim) during 2008-17. In (a), the blue and red shading areas represent the overestimation and underestimation relative to observations, respectively. The small inset in (b) represents the frequency when the intensity was smaller than $10 \mathrm{~mm} \mathrm{day}^{-1}$.

of 10 years from 2008 to 2017 can provide large size of the sample to fit the daily frequency distribution.

\section{Evaluation}

Figure 4 shows the spatial distribution of biases for the TX, PR, RH, and WS in the final downscaled dataHDM. Here, only the evaluation on TX is shown for simplicity, and the results based on TA and TN were similar. Both the TX and PR were very well represented by the HDM output, with biases of $\pm 1^{\circ} \mathrm{C}$ for TX in December-February (DJF) and June-August (JJA), biases of $-0.15-0.05 \mathrm{~mm} \mathrm{day}^{-1}$ for PR in DJF, and biases of $-1-0.5 \mathrm{~mm} \mathrm{day}^{-1}$ for PR in JJA over most stations (Figs. $4 \mathrm{a}-\mathrm{d}$ ). The biases for $\mathrm{RH}$ were $\pm 5 \%$, and the biases for WS were $-1-0.5 \mathrm{~m} \mathrm{~s}^{-1}$ in both DJF and JJA over most stations (Figs. $4 \mathrm{e}-\mathrm{h}$ ), thus indicating that both the RH and WS were also well represented by the HDM. Compared with the biases derived from the RCM, the biases in the HDM were largely reduced (Figs. 5a,c,e,g). The distribution of biases shows that the magnitude of biases in the HDM was much smaller than that in the RCM for all variables. Additionally, the much narrower distribution of biases in the HDM indicates that the biases were all very small over a large number of stations.

It was found that the effect of downscaling on the interannual variability was very small. The distribution of biases shows that both the magnitude and distribution shape of biases changed little after statistical downscaling, thus indicating that the interannual variability in HDM was mostly inherited from the RCM data (Figs. 5b,d,f,h). Relative to the observed value of the interannual variability, most of the percentage biases in the HDM were within $\pm 17 \%$, except for TX in DJF, PR in DJF, RH in DJF, and WS in JJA. Besides, the magnitude of interannual variability in HDM was systematically overestimated for TX in JJA and underestimated for TX in DJF and RH in DJF. So caution was required when the interannual variability of TX in DJF and JJA, PR in DJF, RH in DJF, and WS in JJA were analyzed by using the HDM dataset.

As pointed out by Haerter et al. (2011), the improvements to the statistical properties of the data are limited to the specific time scale of the fluctuations that are considered, which is the daily scale in our study. Our procedure includes delta correction on an annual cycle, QM correction on daily scales, and preservation of the long-term trend, however, the correction on interannual variation is not conducted specifically. So only when daily and interannual fluctuations are aligned will the QM bias correction or statistical downscaling lead to improvements on both time scales. Similar conclusions were also found in our previous studies on QM correction (Tong et al. 2017; Han et al. 2018). The cascade bias-correction method described by Haerter et al. (2011) can solve this flaw, which will be considered in future.

Figures $6 \mathrm{a}$ and $6 \mathrm{~b}$ present the Taylor diagrams of extreme temperature and precipitation indices for HDM compared to the station observations, respectively. The HDM well reproduced all temperature-related indices with high CORs and low normalized RMSEs. The CORs were all larger than 0.95 , and the ratios of variances of the HDM to the observations were mainly around 1 (Fig. 6a). Compared with that of temperature-related indices, the CORs for precipitation-related indices were lower but still significant, and most values were higher than 0.8 except for that of CDD $(-0.30)$ and CWD (0.13). Except for that of CDD (1.93) and CWD (1.45), the ratios of variances of the HDM to the observations were 

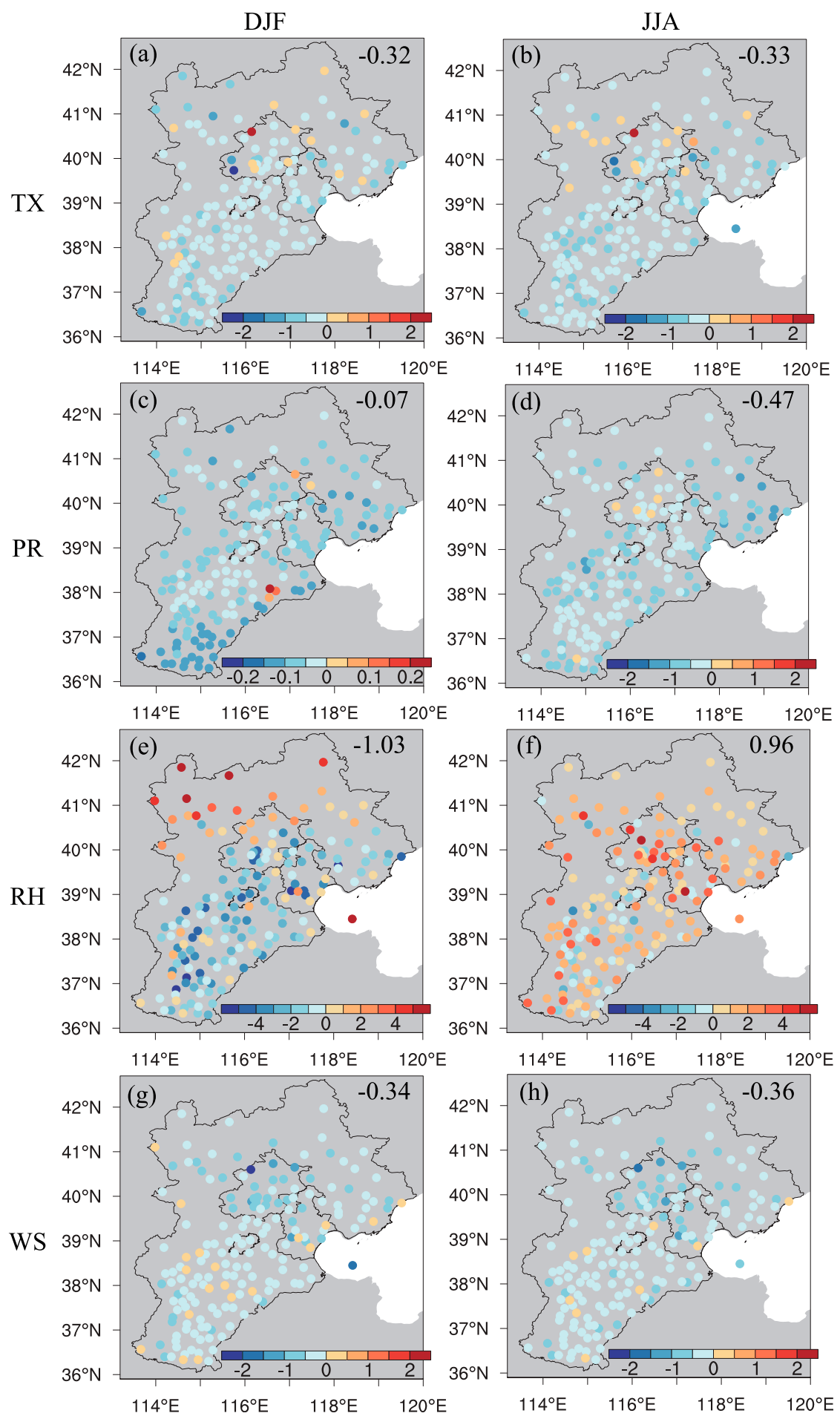

FIG. 4. Biases of downscaled values in HDM over BTH during $2008-17$ for (a),(b) TX $\left({ }^{\circ} \mathrm{C}\right)$, (c),(d) PR $\left(\mathrm{mm} \mathrm{day}^{-1}\right),(\mathrm{e}),(\mathrm{f}) \mathrm{RH}(\%)$, and (g), (h) WS $\left(\mathrm{m} \mathrm{s}^{-1}\right)$ in (left) DJF and (right) JJA. The biases averaged over BTH are listed in each panel. 
(a)
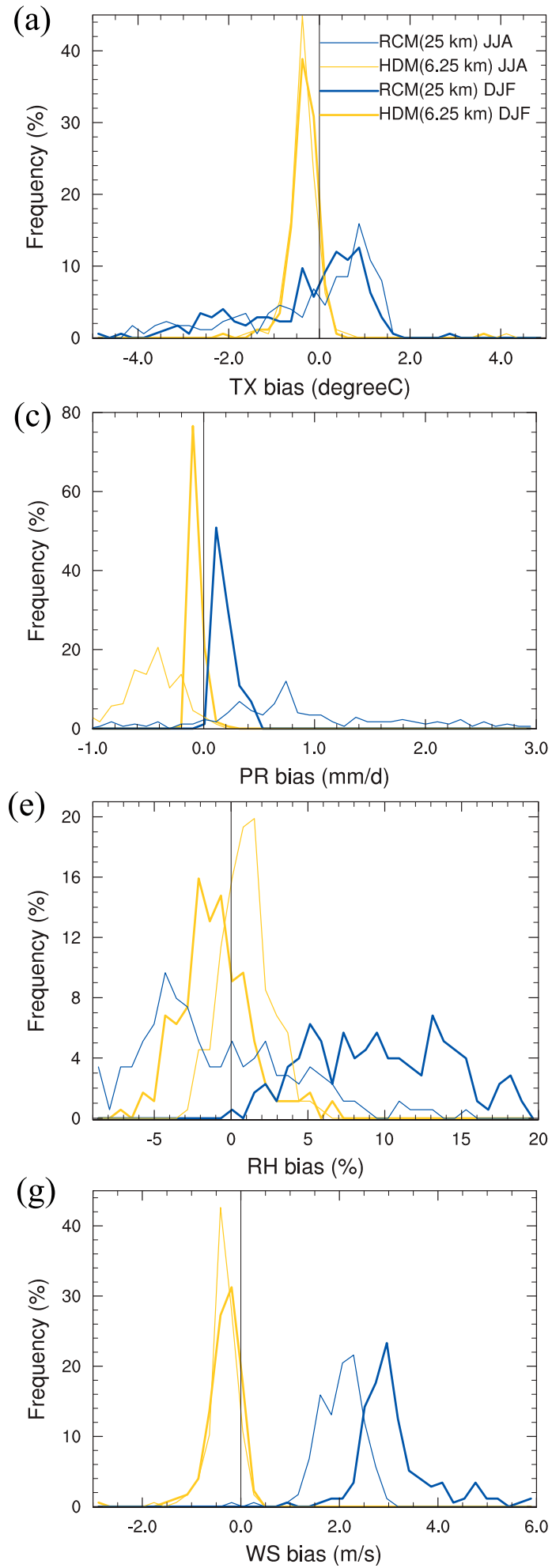
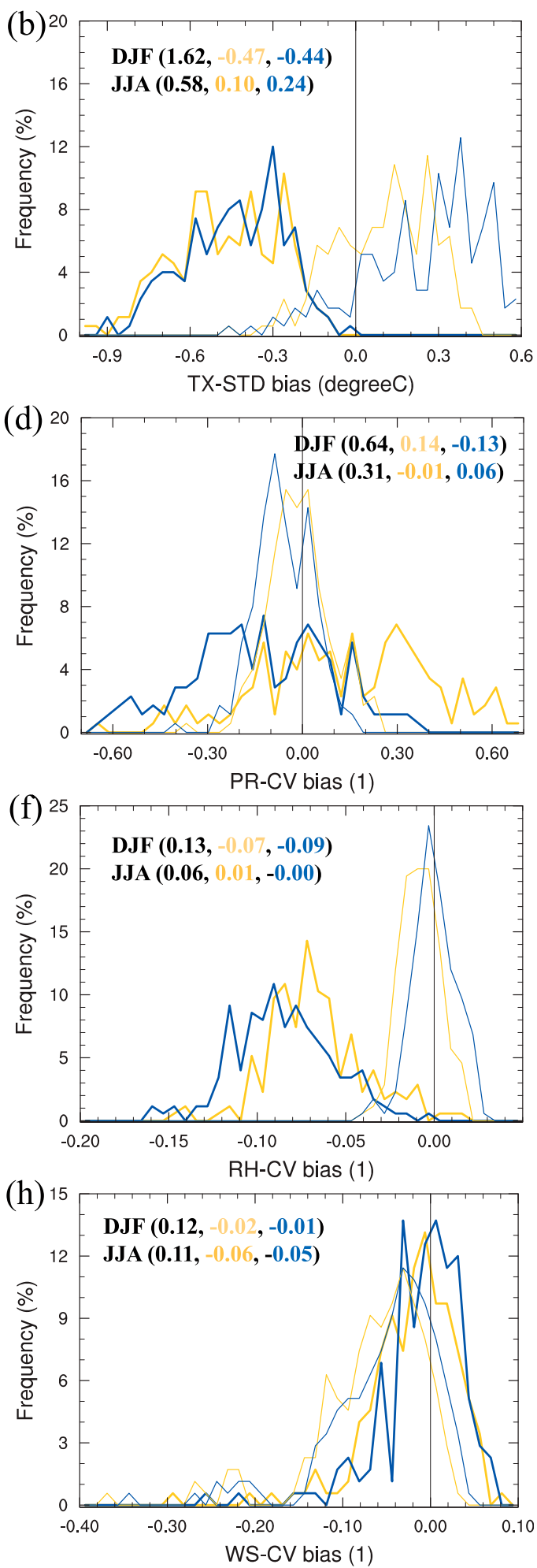

FIG. 5. Relative frequency (\%) of the (left) multiyear mean bias and (right) interannual variability bias in DJF (thick lines) and JJA (thin lines) over BTH during 2008-17 for (a),(b) TX, (c),(d) PR, (e),(f) RH, and (g),(h) WS derived from the HDM (gold lines) and RCM (blue lines). For TX, the magnitude of interannual variations was measured by the interannual standard deviation; for the other variables, the magnitude of variations was measured by the coefficient of variation. In (b), (d), (f), and (h), the observed mean value and biases for the magnitude of interannual variations in the HDM and RCM are listed sequentially. 

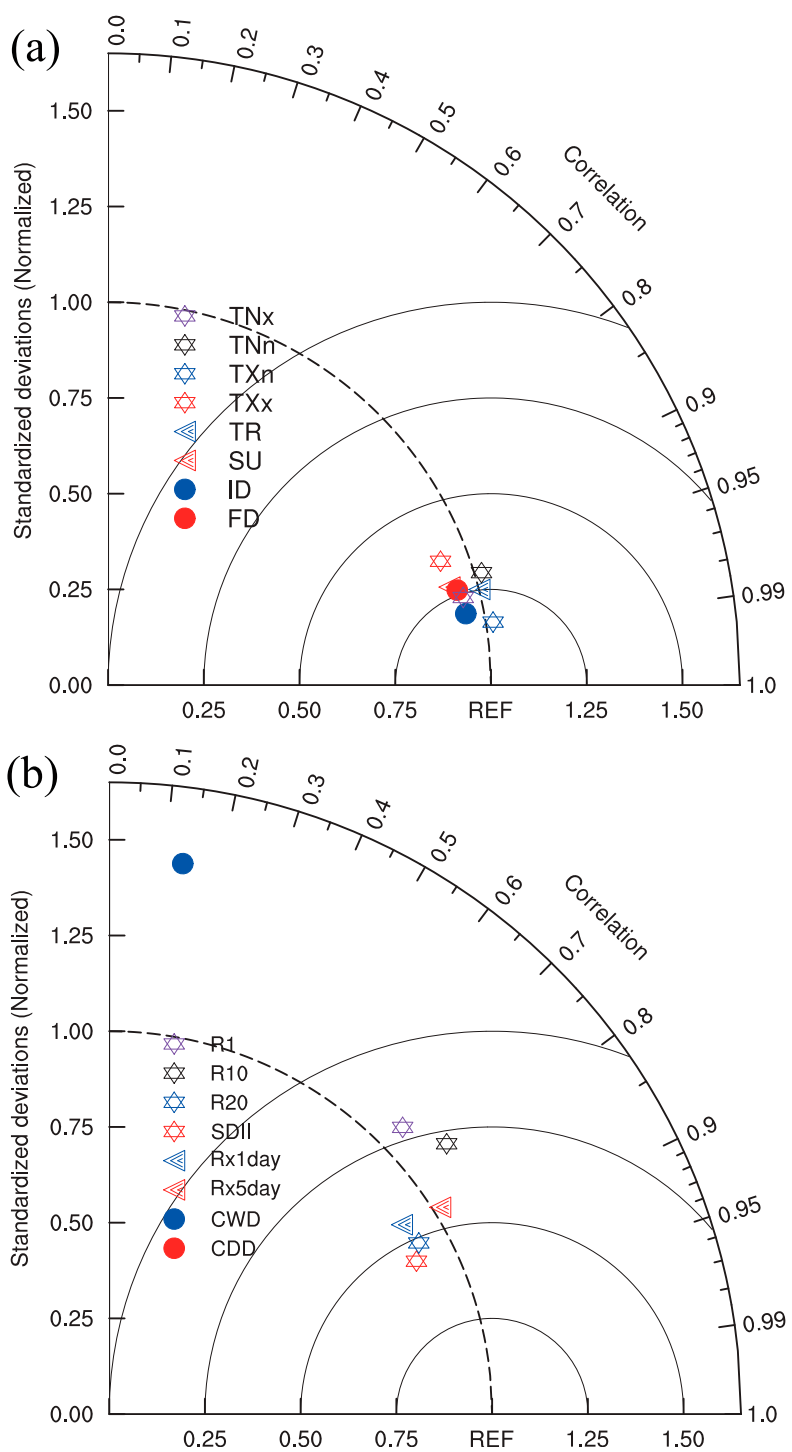

FIG. 6. Taylor diagram for (a) extreme temperature indices and (b) extreme precipitation indices in HDM compared with the observations obtained by using the station data. The marker for CDD is not plotted in (b) because it is located outside the axis limits $(\mathrm{COR}=-0.30$; normalized $\mathrm{RMSE}=1.93)$.

mainly around 1 (Fig. 6b). The reason for the low CORs and high RMSEs in the two consecutive days indices was partly due to the uncertainty in the observations. There were big differences in the CDD and CWD between the station data and CLDAS, and the CORs of CDD and CWD between these two observation datasets were -0.12 and 0.40 , respectively, while the CORs of other precipitation-related indices were all within 0.75-0.92.

\section{Application example}

The kilometer-scale HDM dataset has important application value on the projection studies over regional or local river basins. The New Area city Xiong'an is located in the plain area of the Daqinghe River basin. This basin encompasses most of Hebei Province, a small portion of Shanxi Province, and portions of the Beijing and Tianjin municipalities. The landmass of the basin can be divided into the following three major geographic subregions from west to east: the mountainous area, the western plain, and the eastern plain. The boundary between the western and eastern plain crosses Baiyangdian Lake, which is located at the center of Xiong'an city (Fig. 1b). The construction and development of this new city will be impacted by climate change, so future climate and water resource issues are of concern (Wu et al. 2018). In this study, the climate projections for the whole BTH region, particularly the Daqinghe River basin are used as an example to illustrate the application of this downscaled HDM dataset (the same downscaling procedure was conducted over the small portion belonging to Shanxi Province). All future projections are reported as the change from the 1986-2005 baseline to 2046-65 future periods (midcentury). It is a preliminary analysis on climate projections for the BTH region and the Daqinghe River basin, and studies consisting of projections over the whole $\mathrm{BTH}$ region on climate extremes has been published in Shi et al. (2019) and on exposure to heat stress will be published in R. Li et al. (2019), respectively.

\section{a. Changes in mean climate}

Figures $7 \mathrm{a}$ and $7 \mathrm{~b}$ show the projected changes in the mean annual temperature and precipitation in the middle century from the ensemble mean of five members in HDM. Both the annual temperature and precipitation will increase over most regions in the BTH, except that there are decreases of annual precipitation by mostly less than $2 \%$ over the northeastern part of Beijing and regions close to northern and southeastern border of Hebei Province. All five members in HDM showed a positive temperature change. The ensemble projection in HDM simulated pronounced warming (more than $1.71^{\circ} \mathrm{C}$ ) over the mountainous area and the coastal area at the northern part of Hebei Province, where the maximum warming magnitudes can exceed $1.75^{\circ} \mathrm{C}$. Milder temperature increases $\left(1.60^{\circ}-1.69^{\circ} \mathrm{C}\right)$ mostly locate over the plain area of $\mathrm{BTH}$, and the magnitude of warming has a decline trend from the north to the south (Fig. 7a). The ensemble projection in HDM simulated the largest precipitation increase (more than $10 \%$ ) mostly within the Daqinghe River basin. Less than four members in five agreed on the sign of precipitation change over most mountainous area of northern BTH (the altitude is higher than $1000 \mathrm{~m}$ ), the northeastern part of Beijing, part of the coastal area at the northern part of Hebei 

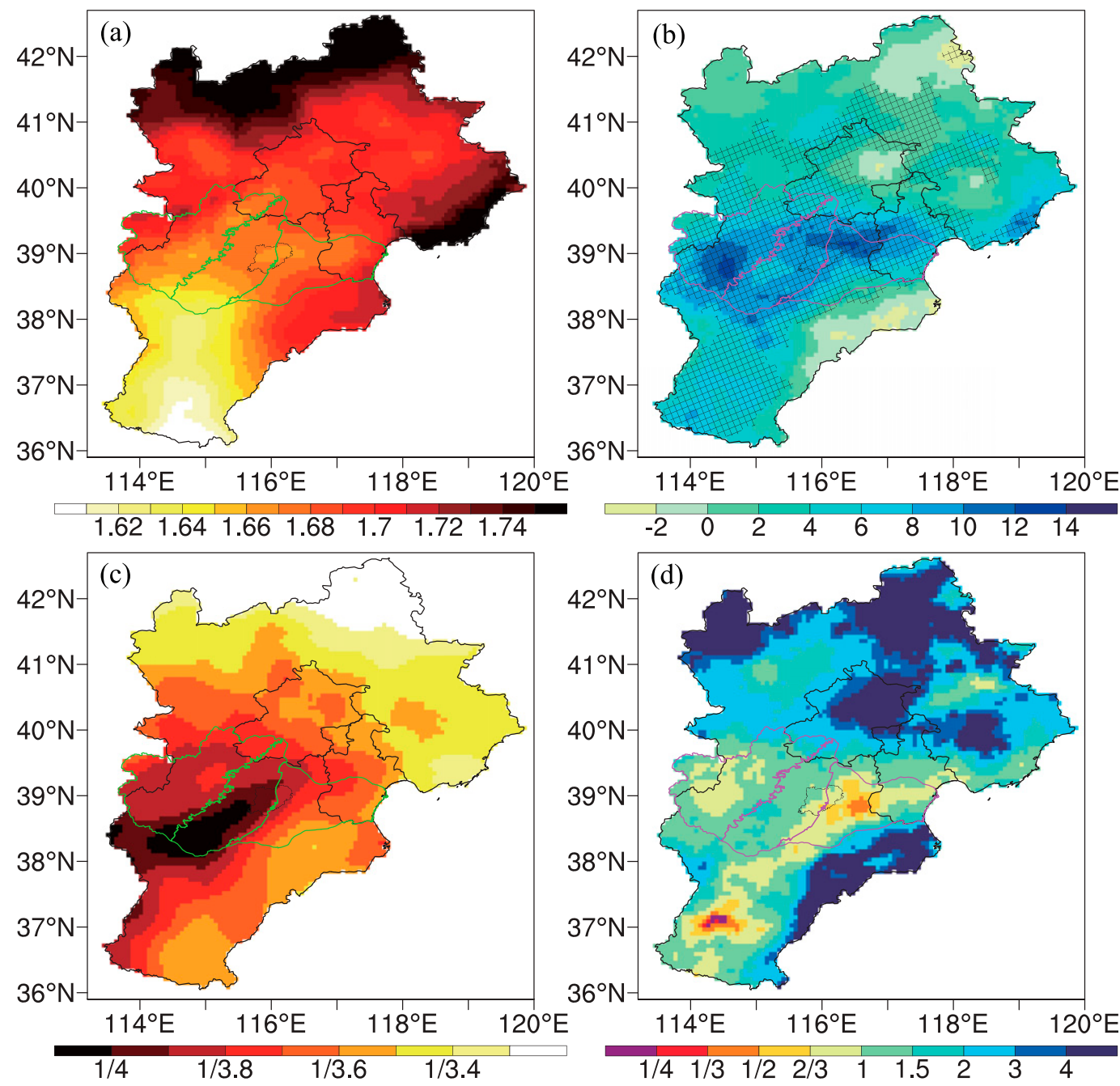

FIG. 7. Multimodel projected annual mean (a) changes of temperature $\left({ }^{\circ} \mathrm{C}\right)$ and (b) relative changes of precipitation (\%) over BTH during 2046-65 relative to 1986-2005, under RCP4.5; also shown is the ratio between the intermodel spread and mean change for (c) temperature and (d) precipitation. Hatched areas in (b) indicate that $80 \%$ or more of ensemble members agree on the sign of change. Agreement on the sign of the change was found everywhere for temperature, and therefore these data are not shown in (a). Green or pink lines in each panel show the location of the Daqinghe River basin and three subregions in this basin.

Province, and regions close to southeastern border of Hebei Province, where the ensemble mean of relative change was less than $4 \%$ (Fig. 7 b).

For the Daqinghe River basin, the overall spatial patterns of simulated changes in the mean annual temperature and precipitation in HDM were generally consistent with the ensemble projections from four $25-\mathrm{km}$ RCMs [Fig. 4a in Wu et al. (2018)], and the results indicate that both the temperature and precipitation will increase over all grids in this basin. Moreover, the results indicate that the warming or wetting magnitudes over the western plain will be relatively weaker or stronger, respectively, when compared with the other two subregions. The ensemble projection in HDM simulated pronounced warming $\left(1.65^{\circ}-1.71^{\circ} \mathrm{C}\right)$ over the mountainous area and eastern plain, and milder temperature increases $\left(1.63^{\circ}\right.$ $1.68^{\circ} \mathrm{C}$ ) over the western plain. The maximum warming magnitudes (more than $1.70^{\circ} \mathrm{C}$ ) were located at the highest mountain regions in the west and coastal regions in the east (Fig. 7a). Four or five members in five agreed on the sign of precipitation change over most regions except the highest mountain regions in the west and marginal regions in the southeast, where the ensemble mean of relative change was less than $2 \%$. The ensemble projection in HDM simulated the largest precipitation increase (more than $12 \%$ ) over the southeastern part of the mountainous area and the northern part of the plain area (Fig. 7b). 
TABLE 1. Ensemble averages of projected changes and uncertainty (as indicated by the standard deviation shown in parentheses) for the annual (ANN) and seasonal mean temperature $\left(\mathrm{TA} ;{ }^{\circ} \mathrm{C}\right)$ and precipitation $(\mathrm{PR} ; \%)$ averaged over the $\mathrm{BTH}$ region, the Daqinghe River basin, three subregions in the basin, and Xiong'an city during 2046-65, under RCP4.5.

\begin{tabular}{|c|c|c|c|c|c|c|c|}
\hline & & BTH & Daqinghe & Mountain & Western plain & Eastern plain & Xiong'an \\
\hline \multirow[t]{5}{*}{ TA } & ANN & $1.70(0.47)$ & $1.67(0.44)$ & $1.67(0.44)$ & $1.66(0.42)$ & $1.67(0.46)$ & $1.66(0.43)$ \\
\hline & DJF & $1.69(0.48)$ & $1.60(0.46)$ & $1.62(0.47)$ & $1.56(0.45)$ & $1.62(0.45)$ & $1.58(0.45)$ \\
\hline & MAM & $1.45(0.46)$ & $1.47(0.40)$ & $1.48(0.41)$ & $1.47(0.38)$ & $1.44(0.43)$ & $1.45(0.39)$ \\
\hline & JJA & $1.90(0.55)$ & $1.91(0.52)$ & $1.87(0.49)$ & $1.93(0.52)$ & $1.93(0.57)$ & $1.94(0.54)$ \\
\hline & SON & $1.74(0.59)$ & $1.70(0.57)$ & $1.72(0.61)$ & $1.67(0.55)$ & $1.71(0.56)$ & $1.68(0.54)$ \\
\hline \multirow[t]{5}{*}{ PR } & ANN & $4.5(5.0)$ & $8.3(8.3)$ & $8.0(8.7)$ & $9.4(11.7)$ & $7.6(6.0)$ & $9.2(8.3)$ \\
\hline & DJF & $26.4(31.3)$ & $34.0(43.5)$ & $31.1(44.5)$ & $34.5(35.7)$ & $37.4(51.2)$ & $41.8(32.5)$ \\
\hline & MAM & $3.4(8.8)$ & $2.9(9.1)$ & $1.5(5.2)$ & $1.4(12.0)$ & $6.3(14.1)$ & $0.5(19.1)$ \\
\hline & JJA & $2.2(11.6)$ & $5.0(17.0)$ & 4.9 (15.7) & $6.6(22.6)$ & $3.8(16.9)$ & $5.5(21.7)$ \\
\hline & SON & $14.8(14.7)$ & $24.2(17.4)$ & $24.1(15.2)$ & $27.1(18.0)$ & $21.6(23.0)$ & $26.5(21.3)$ \\
\hline
\end{tabular}

Besides counting the number of models with the same sign of change, another measure was used to determine the uncertainty of the future change across the ensemble members, namely, the standard deviation of their changes (intermodel spread). Figures $7 \mathrm{c}$ and $7 \mathrm{~d}$ show the ratio between the intermodel spread and mean change for the annual mean temperature and precipitation. For the annual mean temperature, the ensemble standard deviation of the changes was smaller than the amplitude of changes everywhere, with ratios of about 1:4-1:3.2. The smallest ratio (smaller than 1:4) was located at the central part of BTH plain, which indicates that the lowest uncertainty in temperature change occurred here; while the largest uncertainty with the ratio larger than 1:3.2 was located at the mountainous area close to northern border of Hebei Province (Fig. 7c). For annual mean precipitation, the ratios smaller than 1 were located mainly at the central and southern part of BTH plain area where the ensemble projected changes agreed well and the ensemble mean of relative change was greater than $6 \%$, while the ratios larger than 3 were located at the area where disagreement on the sign of the change occurs (Fig. 7d).

For the Daqinghe River basin, the ratios between ensemble standard deviation of the changes in the annual mean temperature and the amplitude of changes were about 1:4-1:3.5. The magnitude of the ratio decreased from northeast to southwest in the mountainous and western plain area, and it decreased from east to west in the eastern plain area. The smallest ratio (smaller than 1:4) was located at the southwestern part of the western plain area, which indicates that the lowest uncertainty in temperature change occurred over this region (Fig. 7c). For annual mean precipitation, the ratios smaller than 1 were located mainly at the eastern plain and mountainous area, and the ratios at the western plain were about 1-1.5. The smallest ratio (smaller than 1:3) was located at the central part of eastern plain, while the largest ratio (larger than 2) was located at the northern part of the mountainous area (Fig. 7d).

At the seasonal scale, spatial averages of the projected changes and ensemble standard deviations using all of the grid points within a certain region were computed, including the values over the whole $\mathrm{BTH}$ region, the whole Daqinghe River basin, the three subregions in the basin, and Xiong'an city (Table 1). For the whole BTH region, the warming was higher in $\mathrm{JJA}\left(1.90^{\circ} \mathrm{C}\right)$ than in September-November $\left(\mathrm{SON} ; 1.74^{\circ} \mathrm{C}\right)$ and $\mathrm{DJF}\left(1.69^{\circ} \mathrm{C}\right)$, and the magnitude in March-May (MAM; $1.45^{\circ} \mathrm{C}$ ) was the lowest. These characteristics of seasonal differences were similar over the Daqinghe River basin, three subregions, and Xiong'an city. For all regions, the intermodel spread was highest in SON or JJA, then in DJF, and the value in MAM was the lowest. Following derivation of the ratio between the intermodel spread and mean change (Table 2), the range of ratios was $0.26-0.35$ (1:3.8-1:2.9). The ratios were highest in SON for all of the regions, thus indicating that the largest uncertainty for temperature change occurred in this season, and the lowest ratios occurred in DJF for the whole BTH region and the eastern plain of Daqinghe River basin, MAM for the western plain of Daqinghe River basin and Xiong'an, and JJA for the mountainous area of Daqinghe River basin.

The relative change of precipitation averaged over the whole BTH region was largest in DJF, then in SON, and the value was lowest in JJA and MAM (Table 1). Because the climatological mean value in DJF was very small, the absolute change was largest in SON $(12.7 \mathrm{~mm})$, then in JJA $(3.0 \mathrm{~mm})$, and the value was lowest in DJF $(1.0 \mathrm{~mm})$ and MAM $(1.6 \mathrm{~mm})$. These characteristics of seasonal differences were similar over the Daqinghe River basin, the three subregions and Xiong'an city. The magnitudes of projected change over the Daqinghe River basin were larger than those over BTH in DJF, JJA, and SON, because the maximum increase magnitudes were all located 
TABLE 2. The ratio between the intermodel spread and ensemble mean change of the annual and seasonal mean temperature and precipitation averaged over the BTH region, the Daqinghe River basin, three subregions in the basin, and Xiong'an city, and the number of models with the same sign of change (shown in parentheses) during 2046-65, under RCP4.5. The number of models with the same sign of change was five in all regions and seasons for temperature, and therefore these data are not shown.

\begin{tabular}{|c|c|c|c|c|c|c|c|}
\hline & & ВTH & Daqinghe & Mountain & Western plain & Eastern plain & Xiong'an \\
\hline \multirow[t]{5}{*}{ TA } & ANN & 0.28 & 0.26 & 0.26 & 0.25 & 0.27 & 0.26 \\
\hline & DJF & 0.28 & 0.29 & 0.29 & 0.29 & 0.28 & 0.28 \\
\hline & MAM & 0.32 & 0.27 & 0.27 & 0.26 & 0.29 & 0.27 \\
\hline & JJA & 0.29 & 0.27 & 0.26 & 0.27 & 0.30 & 0.28 \\
\hline & SON & 0.34 & 0.34 & 0.35 & 0.33 & 0.33 & 0.32 \\
\hline \multirow[t]{5}{*}{ PR } & ANN & $1.1(4)$ & $1.0(4)$ & $1.1(4)$ & $1.2(4)$ & $0.8(4)$ & $0.9(4)$ \\
\hline & DJF & $1.2(4)$ & $1.3(4)$ & $1.4(4)$ & $1.0(5)$ & $1.4(4)$ & $0.8(5)$ \\
\hline & MAM & $2.6(3)$ & $3.1(2)$ & $3.4(3)$ & $8.4(2)$ & $2.2(3)$ & $35.9(2)$ \\
\hline & JJA & $5.2(3)$ & $3.4(2)$ & $3.2(3)$ & $3.4(2)$ & $4.5(3)$ & $3.9(2)$ \\
\hline & SON & $1.0(4)$ & $0.7(4)$ & $0.6(4)$ & $0.7(4)$ & $1.1(4)$ & $0.8(4)$ \\
\hline
\end{tabular}

inside the Daqinghe River basin in those seasons (figures not shown). The ratios between the intermodel spread and mean change were calculated over each region and each season (Table 2). The data show that the uncertainty was lowest in SON, with a ratio no larger than 1 at each region except for the eastern plain of the Daqinghe River basin (ratio = 1.1). The uncertainty was medium in DJF with ratios of 0.8-1.2, and the uncertainty was highest in MAM and JJA with ratios generally larger than 3. By counting the number of models with the same sign of change, it was also found that the uncertainty was lower in SON and DJF (four or five members in five agreed on the sign), while the uncertainty was higher in MAM and JJA (two or three members in five agreed on the sign).

\section{b. Changes in extreme climate}

Two extreme temperature indices-TR and TXx and two precipitation indices- $\mathrm{R} 20$ and $\mathrm{Rx} 5$ day were chosen to illustrate the future changes in extreme heat and heavy precipitation events (Figs. 8 and 9). The ensemble results projected an increasing tendency of both TR and TXx over the whole BTH. The plain area of BTH in the future may suffer more frequent and more intense hot days, in addition to the disasters in recent years (Deng et al. 2018), with much larger increases of TR and TXx when compared with the mountainous area. The increasing value of TR averaged over the BTH and the Daqinghe River basin was 18.84 and 23.34 days, respectively. The value of TR nearly does not change in the higher mountain area in the northern BTH, an area characterized by low values already in the past. Inside the Daqinghe River basin, the increasing magnitude of TR was also smaller over the mountainous area (19.30 days) than that over the western plain (27.08 days) and eastern plain (25.31 days). Compared to TR, the spatial range of change in TXx was smaller. The increasing value of TXx averaged over the $\mathrm{BTH}$ and the Daqinghe River basin was $1.87^{\circ}$ and $1.93^{\circ} \mathrm{C}$, respectively, and the maximum difference among subregions of the basin was about $0.8^{\circ} \mathrm{C}$ (Figs. 8a,b).

All five members in HDM showed a positive change in TR and TXx. The ratios between ensemble standard deviation of the changes and the amplitude of changes were about 1:6-1:3 over the BTH plain area for both TR and TXx, and the ratios were higher (lower) for TR (TXx) over the BTH mountainous area (Figs. 8c,d). So the uncertainty for TR over the Daqinghe River basin (the ratio is 0.21 ) was smaller than that over the whole BTH (the ratio is 0.24), while the uncertainty for TXx over the Daqinghe River basin (the ratio is 0.18 ) was larger than that over the whole BTH (the ratio is 0.16 ). Inside the Daqinghe River basin, the uncertainty for TR (TXx) was also larger (smaller) over the mountainous area, compared to that over the western and eastern plain (Table 3).

The ensemble results projected overall increase of two precipitation indices- $-\mathrm{R} 20$ and Rx5day. The spatial pattern of changes in Rx5day was similar to that for annual precipitation, but very different from that for R20. There are decreases of R20 by mostly less than $15 \%$ over regions close to northern, northeastern, and southeastern border of Hebei Province and decreases of Rx5day by mostly less than $10 \%$ over the northeastern part of Beijing and regions close to northern and southeastern border of Hebei Province. The ensemble projection in HDM simulated that more than half of regions with the large extreme precipitation increase (more than 15\% change in both R20 and Rx5day) were located within the Daqinghe River basin (Figs. 9a,b). So the relative changes in R20 and Rx5day averaged over the Daqinghe River basin $(19.1 \%$ and $15.3 \%)$ were larger than those averaged over the whole BTH $(10.2 \%$ and $10.4 \%)$. Inside the Daqinghe River basin, the relative changes in R20 were much larger over the mountainous area $(23.5 \%)$ and the western plain $(19.6 \%)$ than those over 

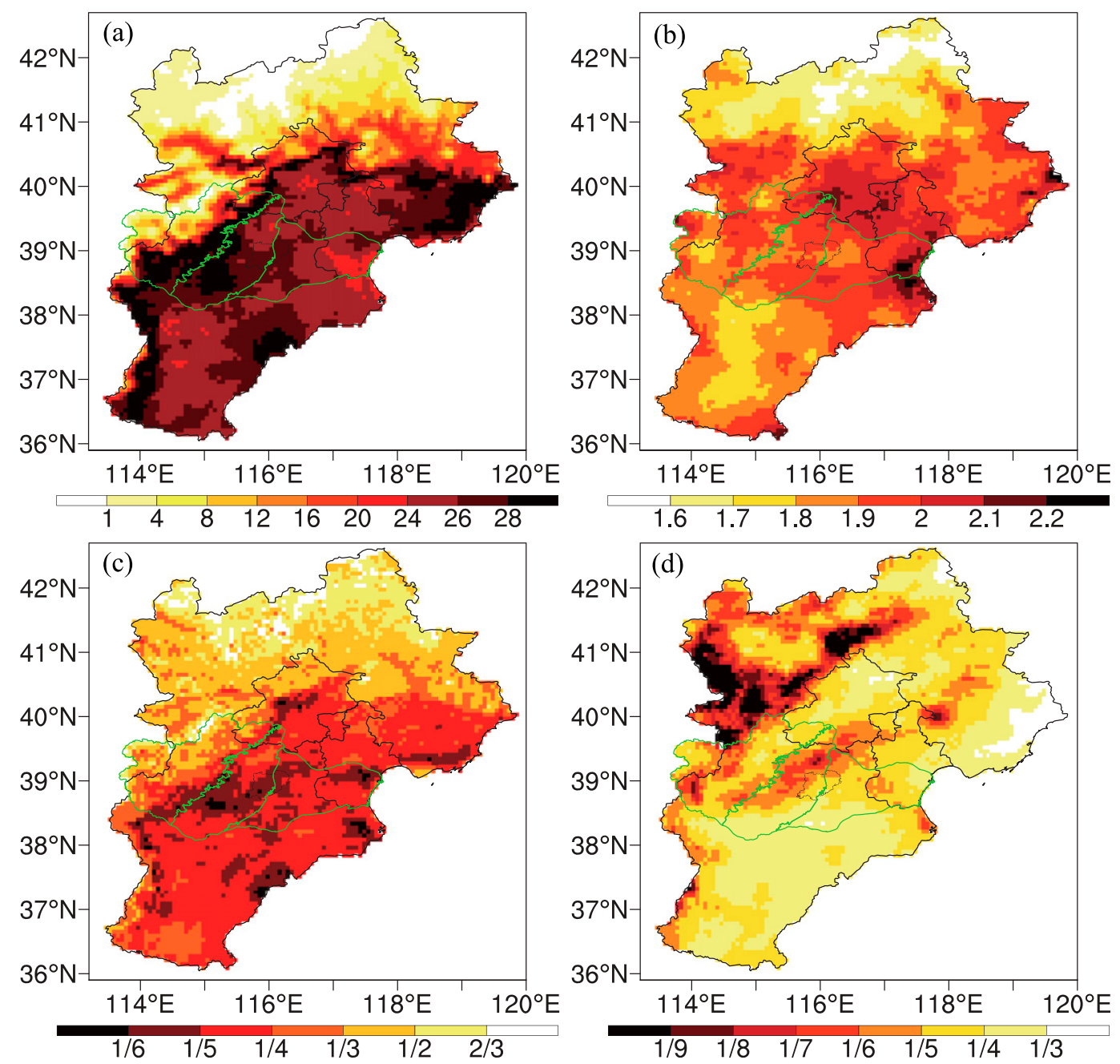

FIG. 8. Multimodel projected changes of (a) TR (days) and (b) TXx $\left({ }^{\circ} \mathrm{C}\right.$ ) over BTH during $2046-65$ relative to 1986-2005, under RCP4.5; also shown is the ratio between the intermodel spread and mean change for (c) TR and (d) TXx. Agreement on the sign of the change was found everywhere for temperature indices, and therefore these data are not shown in (a) and (b). Green lines in each panel show the location of the Daqinghe River basin and three subregions in this basin.

the eastern plain $(12.7 \%)$, while spatial variation of Rx5day change across the basin was small (Table 3 ).

Four or five members in five agreed on the sign of R20 and $\mathrm{Rx} 5$ day change over most regions with the ensemble mean change larger than $5 \%$. Considering grids with the ratio between ensemble standard deviation of the changes and the amplitude of changes no larger than 1 , the area of these grids for R20 was much larger than that for Rx5day, and they were mostly (partly) located within the Daqinghe River basin for R20 (Rx5day). The uncertainty for R20 was also lower over these grids than that for Rx5day (Figs. 9c,d). For spatial averages of the projected changes, all regions could pass the threshold on agreement (no less than $80 \%$ ), and only the member forced by the GCM of MPI-ESM-MR was a significant outlier (figure not shown). The uncertainties indicated by the ratio were lower for R20 with the value of $0.5-1.0$ than those for Rx5day with value of $0.8-1.4$. Inside the Daqinghe River basin, the uncertainties over the western plain for both R20 and Rx5day were slightly higher than those over two other subregions in the basin (Table 3).

\section{Conclusions}

A downscaling system (HDM) that couples dynamical and statistical downscaling (RCM and QM) was constructed over the BTH region. The evaluation showed that the HDM output can well reproduce the mean states of all variables, all extreme temperature indices, and most of the extreme precipitation indices. The biases of 

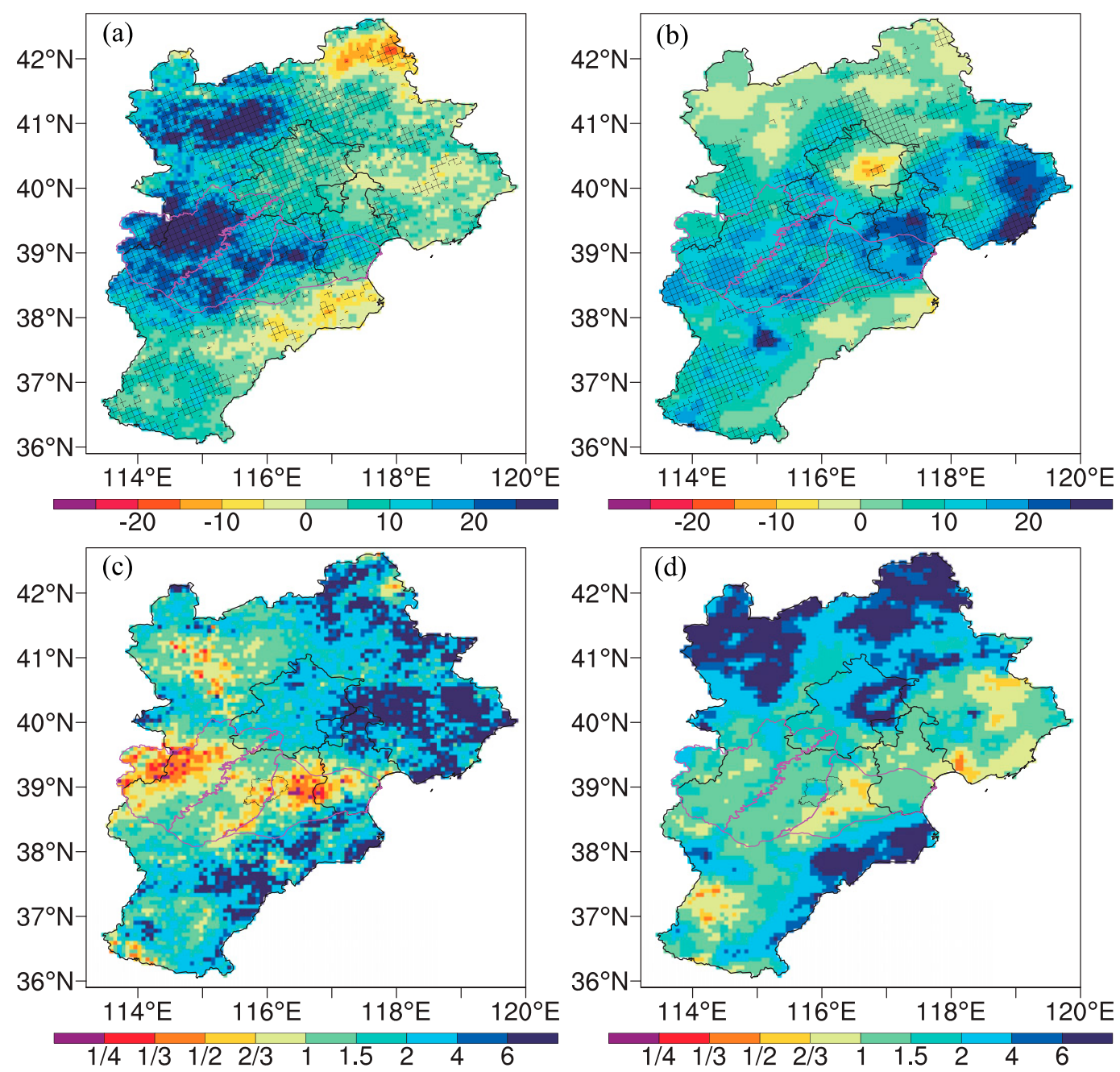

FIG. 9. Multimodel projected relative changes (\%) of (a) R20 and (b) Rx5day over BTH during 2046-65 relative to 1986-2005, under RCP4.5; also shown is the ratio between the intermodel spread and mean change for (c) R20 and (d) Rx5day. Hatched areas in (a) and (b) indicate that $80 \%$ or more of ensemble members agree on the sign of change. Pink lines in each panel show the location of the Daqinghe River basin and three subregions in this basin.

interannual variability in HDM were mostly inherited from the RCM data, and these biases were larger for temperature in DJF, PR in DJF, RH in DJF, and WS in JJA, so one has to be cautious when the interannual variability is analyzed by using the HDM dataset.
By using the HDM, a case study on future climate projections under RCP4.5 over the whole BTH region was conducted, and the projections over the Daqinghe River basin in BTH were also analyzed in detail. The results showed that the annual mean temperature and

TABLE 3. Ensemble averages of projected changes for TR (day), TXx $\left({ }^{\circ} \mathrm{C}\right), \mathrm{R} 20(\%)$, and Rx5day (\%) and the corresponding uncertainty (as indicated by the ratio between the intermodel spread and ensemble mean change and the number of models with the same sign of change shown, in parentheses sequentially) averaged over the BTH region, the Daqinghe River basin, three subregions in the basin, and Xiong'an city during 2046-65, under RCP4.5.

\begin{tabular}{lcccccc}
\hline \hline & BTH & Daqinghe & Mountain & Western plain & Eastern plain & Xiong'an \\
\hline TR & $18.84(0.24,5)$ & $23.34(0.21,5)$ & $19.30(0.26,5)$ & $27.08(0.20,5)$ & $25.31(0.20,5)$ & $26.44(0.19,5)$ \\
TXx & $1.87(0.16,5)$ & $1.93(0.18,5)$ & $1.90(0.19,5)$ & $1.91(0.19,5)$ & $1.98(0.22,5)$ & $1.91(0.21,5)$ \\
R20 & $10.2(1.0,4)$ & $19.1(0.6,5)$ & $23.5(0.5,5)$ & $19.6(0.9,4)$ & $12.7(0.5,5)$ & $20.4(0.5,5)$ \\
Rx5day & $10.4(0.8,4)$ & $15.3(1.0,4)$ & $13.5(1.2,4)$ & $17.8(1.2,4)$ & $15.4(0.9,4)$ & $12.8(1.4,4)$ \\
\hline
\end{tabular}


precipitation will increase over most regions in the $\mathrm{BTH}$ and over all grids in the Daqinghe River basin, except that precipitation will decrease by mostly less than $2 \%$ over the northeastern part of Beijing and regions close to northern and southeastern border of Hebei Province. The warming magnitudes over the mountainous area and the coastal area at the northern part of Hebei Province and the wetting magnitudes over the Daqinghe River basin will be relatively stronger compared to the other regions. Inside the Daqinghe River basin, the warming magnitudes over the western plain will be relatively weaker when compared with the other two subregions and the wetting magnitudes over the western plain will be relatively stronger.

Both the number of models with the same sign of change and the ensemble standard deviation of the changes were used to estimate the uncertainty of the future change across the ensemble members. The future projection over regions where the agreement on the sign of the change is low or the intermodel spread is larger than the ensemble mean (the ratio is larger than 1) should be considered carefully. The ratio between the intermodel spread and mean change for the annual mean temperature and precipitation was about 1:4-1:3.2 and 1:4-5:1, respectively. Most regions with lowest uncertainty for temperature and about half of regions with lowest uncertainty for precipitation were located at the Daqinghe River basin. Inside the Daqinghe River basin, the lowest uncertainty for temperature was located at the southwestern part of the western plain, and that for precipitation was located at the central part of the eastern plain.

Averaged over the whole BTH, the Daqinghe River basin, and all subregions in the basin, the warming magnitudes were all highest in JJA, then in SON, DJF, and MAM. The uncertainties were highest in SON for all regions, and they were lowest in DJF for the whole BTH region and the eastern plain of Daqinghe River basin, MAM for the western plain of Daqinghe River basin and Xiong'an, and JJA for the mountainous area of Daqinghe River basin. At all regions, the averaged relative change of precipitation was largest in DJF, then in SON, JJA, and MAM. The magnitudes of projected change over the Daqinghe River basin were larger than those over BTH at most seasons. The uncertainty was lower in SON and DJF, while it was higher in MAM and JJA.

Extreme heat events indicated by TR and TXx will increase with much larger magnitude of increase in the plain area when compared with the mountainous area. All five members in HDM showed a positive change in TR and TXx, and the uncertainties indicated by the ratio were very low with value mostly less than $1: 3$ over the plain area for both TR and TXx and slightly higher over the mountainous area for TR. Extreme heavy precipitation events indicated by $\mathrm{R} 20$ and $\mathrm{R} x 5$ day will also increase over most BTH region. More than onehalf of regions with the large extreme precipitation increase were located within the Daqinghe River basin, and most regions with low uncertainties were also located within the basin. The uncertainty for R20 was overall lower than that for Rx5day. Inside the Daqinghe River basin, the uncertainties over the western plain for both R20 and Rx5day were slightly higher than those over two other subregions in the basin.

Performing multimember dynamical downscaling of $6.25-\mathrm{km}$-resolution data using RCMs directly is costly. The present study demonstrated that, by coupling dynamical and statistical downscaling techniques, this system can produce a reliable multivariable, multimember, multidecadal (1980-2099), high-resolution $(6.25 \mathrm{~km})$ product with daily data for climate change projections. This downscaling system can be directly applied to other CORDEX regions and other emission scenarios if quality high-resolution observations are available. Such outputs would provide valuable scientific support for scientists conducting climate impact studies and for policymakers making climate change mitigation and adaptation decisions.

The commonly used statistical downscaling methods consider climate variables independently. However, there are more and more methods focusing on the intervariable relationships, which are based on either MOS (C. Li et al. 2014; Vrac and Friederichs 2015; Cannon 2016; Guo et al. 2019) or PP strategy (Abatzoglou and Brown 2012; Cheng et al. 2017). In this study, when the statistical downscaling was conducted, the relationships between different variables have not been considered and the interannual variation has not been well corrected as we mentioned in the evaluation section. Further studies are needed to overcome these limitations in the future.

Acknowledgments. This work was jointly supported by the National Key Research and Development Program of China (2018YFA0606301, 2016YFC0402405, and 2017YFA0605004) and the National Natural Science Foundation of China (41690141).

\section{REFERENCES}

Abatzoglou, J. T., and T. J. Brown, 2012: A comparison of statistical downscaling methods suited for wildfire applications. Int. J. Climatol., 32, 772-780, https://doi.org/10.1002/joc.2312.

Boé, J., L. Terray, F. Habets, and E. Martin, 2007: Statistical and dynamical downscaling of the Seine basin climate for hydrometeorological studies. Int. J. Climatol., 27, 1643-1655, https:// doi.org/10.1002/joc.1602.

Bucchignani, E., A. L. Zollo, L. Cattaneo, M. Montesarchio, and P. Mercogliano, 2017: Extreme weather events over China: Assessment of COSMO-CLM simulations and future scenarios. Int. J. Climatol., 37, 1578-1594, https://doi.org/10.1002/joc.4798. 
Cannon, A. J., 2016: Multivariate bias correction of climate model output: Matching marginal distributions and intervariable dependence structure. J. Climate, 29, 7045-7064, https://doi.org/ 10.1175/JCLI-D-15-0679.1.

_, S. R. Sobie, and T. Q. Murdock, 2015: Bias correction of GCM precipitation by quantile mapping: How well do methods preserve changes in quantiles and extremes? J. Climate, 28, 69386959, https://doi.org/10.1175/JCLI-D-14-00754.1.

Casanueva, A., and Coauthors, 2016: Daily precipitation statistics in a EURO-CORDEX RCM ensemble: Added value of raw and bias-corrected high-resolution simulations. Climate Dyn., 47, 719-737, https://doi.org/10.1007/s00382-015-2865-x.

Chen, Y. D., J. Li, and Q. Zhang, 2016: Changes in site-scale temperature extremes over China during 2071-2100 in CMIP5 simulations. J. Geophys. Res. Atmos., 121, 2732-2749, https:// doi.org/10.1002/2015JD024287.

Cheng, G., G. Huang, C. Dong, J. Zhu, X. Zhou, and Y. Yao, 2017: Recursive multivariate principal-monotonicity inferential climate downscaling. Quart. J. Roy. Meteor. Soc., 143, 2780-2796, https://doi.org/10.1002/qj.3126.

Deng, K., S. Yang, M. Ting, A. Lin, and Z. Wang, 2018: An intensified mode of variability modulating the summer heat waves in eastern Europe and northern China. Geophys. Res. Lett., 45, 11361-11 369, https://doi.org/10.1029/2018GL079836.

Ehret, U., E. Zehe, V. Wulfmeyer, K. Warrach-Sagi, and J. Liebert, 2012: "Should we apply bias correction to global and regional climate model data?" Hydrol. Earth Syst. Sci., 16, 3391-3404, https://doi.org/10.5194/hess-16-3391-2012.

Fang, G. H., J. Yang, Y. N. Chen, and C. Zammit, 2015: Comparing bias correction methods in downscaling meteorological variables for a hydrologic impact study in an arid area in China. Hydrol. Earth Syst. Sci., 19, 2547-2559, https://doi.org/10.5194/ hess-19-2547-2015.

Fu, G., S. P. Charles, J. Yu, and C. Liu, 2009: Decadal climatic variability, trends, and future scenarios for the North China Plain. J. Climate, 22, 2111-2123, https://doi.org/10.1175/2008JCLI2605.1.

Gao, X., and F. Giorgi, 2017: Use of the RegCM system over East Asia: Review and perspectives. Engineering, 3, 766-772, https:// doi.org/10.1016/J.ENG.2017.05.019.

— river basins in China. Adv. Atmos. Sci., 34, 441-455, https:// doi.org/10.1007/s00376-016-6179-7.

— conditions over China based on multi-RegCM4 simulations. Atmos. Ocean. Sci. Lett., 11, 291-299, https://doi.org/10.1080/ 16742834.2018.1471578.

Giorgi, F., C. Jones, and G. Asrar, 2009: Addressing climate information needs at the regional level: The CORDEX framework. WMO Bull., 58, 175-183.

Grenier, P., 2018: Two types of physical inconsistency to avoid with univariate quantile mapping: A case study over North America concerning relative humidity and its parent variables. J. Appl. Meteor. Climatol., 57, 347-364, https://doi.org/10.1175/JAMCD-17-0177.1.

Gudmundsson, L., J. B. Bremnes, J. E. Haugen, and T. EngenSkaugen, 2012: Technical Note: Downscaling RCM precipitation to the station scale using statistical transformations-A comparison of methods. Hydrol. Earth Syst. Sci., 16, 3383-3390, https://doi.org/10.5194/hess-16-3383-2012.

Guo, Q., J. Chen, X. Zhang, M. Shen, H. Chen, and S. Guo, 2019: A new two-stage multivariate quantile mapping method for bias correcting climate model outputs. Climate Dyn., 53, 3603-3623, https://doi.org/10.1007/s00382-019-04729-w.
Haerter, J. O., S. Hagemann, C. Moseley, and C. Piani, 2011: Climate model bias correction and the role of timescales. Hydrol. Earth Syst. Sci., 15, 1065-1079, https://doi.org/10.5194/hess-15-1065-2011.

Han, Z., B. Zhou, Y. Xu, J. Wu, and Y. Shi, 2017: Projected changes in haze pollution potential in China: An ensemble of regional climate model simulations. Atmos. Chem. Phys., 17, 10 109-10123, https://doi.org/10.5194/acp-17-10109-2017.

—, Y. Tong, X. Gao, and Y. Xu, 2018: Correction based on quantile mapping for temperature simulated by the RegCM4 (in Chinese). Climate Change Res., 14, 331-340.

Hui, P., J. Tang, S. Wang, X. Niu, P. Zong, and X. Dong, 2018: Climate change projections over China using regional climate models forced by two CMIP5 global models. Part I: Evaluation of historical simulations. Int. J. Climatol., 38, e57-e77, https:// doi.org/10.1002/joc.5351.

IPCC, 2015: Workshop on regional climate projections and their use in impacts and risk analysis studies. T. F. Stocker et al., Eds., IPCC Workshop Rep., 171 pp., https://www.ipcc.ch/site/ assets/uploads/2018/05/RPW_WorkshopReport.pdf.

Jiang, R., X. Yu, J. Xie, Y. Zhao, F. Li, and M. Yang, 2018: Recent changes in daily climate extremes in a serious water shortage metropolitan region, a case study in Jing-Jin-Ji of China. Theor. Appl. Climatol., 134, 565-584, https://doi.org/10.1007/s00704017-2293-4.

Kang, S., and E. A. B. Eltahir, 2018: North China Plain threatened by deadly heatwaves due to climate change and irrigation. Nat. Commun., 9, 2894, https://doi.org/10.1038/s41467-018-05252-y.

Karl, T. R., N. Nicholls, and A. Ghazi, 1999: Clivar/GCOS/WMO Workshop on Indices and Indicators for Climate Extremes Workshop Summary. Climatic Change, 42, 3-7, https://doi.org/ 10.1023/A:1005491526870.

Kim, M.-K., S. Kim, J. Kim, J. Heo, J.-S. Park, W.-T. Kwon, and M.-S. Suh, 2016: Statistical downscaling for daily precipitation in Korea using combined PRISM, RCM, and quantile mapping: Part 1, methodology and evaluation in historical simulation. Asia-Pac. J. Atmos. Sci., 52, 79-89, https://doi.org/10.1007/s13143-016-0010-3.

Li, C., E. Sinha, D. E. Horton, N. S. Diffenbaugh, and A. M. Michalak, 2014: Joint bias correction of temperature and precipitation in climate model simulations. J. Geophys. Res. Atmos., 119, 13 153-13 162, https://doi.org/10.1002/2014JD022514.

Li, D., L. Zou, and T. Zhou, 2018: Extreme climate event changes in China in the 1.5 and $2^{\circ} \mathrm{C}$ warmer climates: Results from statistical and dynamical downscaling. J. Geophys. Res., 123, 10 215-10 230, https://doi.org/10.1029/2018JD028835.

Li, H., J. Sheffield, and E. F. Wood, 2010: Bias correction of monthly precipitation and temperature fields from Intergovernmental Panel on Climate Change AR4 models using equidistant quantile matching. J. Geophys. Res., 115, D10101, https://doi.org/10.1029/2009JD012882.

Li, P., K. Furtado, T. Zhou, H. Chen, J. Li, Z. Guo, and C. Xiao, 2019: The diurnal cycle of East Asian summer monsoon precipitation simulated by the Met Office Unified Model at convectionpermitting scales. Climate Dyn., https://doi.org/10.1007/s00382018-4368-Z, in press.

Li, R., Z. Han, Y. Xu, Y. Shi, and J. Wu, 2019: An ensemble projection of GDP and population exposure to high temperature events over Jing-Jin-Ji district based on high resolution $(6.25 \mathrm{~km})$ combined dynamical and statistical downscaling datasets (in Chinese). Climate Change Res., in press.

Li, T., and Coauthors, 2014: Mapping near-surface air temperature, pressure, relative humidity and wind speed over Mainland China with high spatiotemporal resolution. Adv. Atmos. Sci., 31, 1127-1135, https://doi.org/10.1007/s00376-014-3190-8. 
Liu, W., G. Fu, C. Liu, X. Song, and R. Ouyang, 2013: Projection of future rainfall for the North China Plain using two statistical downscaling models and its hydrological implications. Stochastic Environ. Res. Risk Assess., 27, 1783-1797, https:// doi.org/10.1007/s00477-013-0714-1.

Maraun, D., and Coauthors, 2010: Precipitation downscaling under climate change: Recent developments to bridge the gap between dynamical models and the end user. Rev. Geophys., $\mathbf{4 8}$, RG3003, https://doi.org/10.1029/2009RG000314.

Meng, X., and H. Wang, 2017: Significance of the China Meteorological Assimilation Driving Datasets for the SWAT Model (CMADS) of East Asia. Water, 9, 765, https://doi.org/10.3390/ w9100765.

Piani, C., G. Weedon, M. Best, S. Gomes, P. Viterbo, S. Hagemann, and J. Haerter, 2010: Statistical bias correction of global simulated daily precipitation and temperature for the application of hydrological models. J. Hydrol., 395, 199-215, https://doi.org/ 10.1016/j.jhydrol.2010.10.024.

Reder, A., G. Rianna, R. Vezzoli, and P. Mercogliano, 2016: Assessment of possible impacts of climate change on the hydrological regimes of different regions in China. Adv. Climate Change Res., 7, 169-184, https://doi.org/10.1016/j.accre.2016.09.002.

Reiter, P., O. Gutjahr, L. Schefczyk, G. Heinemann, and M. Casper, 2016: Bias correction of ENSEMBLES precipitation data with focus on the effect of the length of the calibration period. $M e$ teor. Z., 25, 85-96, https://doi.org/10.1127/metz/2015/0714.

Shen, Y., P. Zhao, Y. Pan, and J. Yu, 2014: A high spatiotemporal gauge-satellite merged precipitation analysis over China. J. Geophys. Res., 119, 3063-3075, https://doi.org/ 10.1002/2013JD020686.

Shi, C., Z. Xie, H. Qian, M. Liang, and X. Yang, 2011: China land soil moisture EnKF data assimilation based on satellite remote sensing data. Sci. China Earth Sci., 54, 1430-1440, https:// doi.org/10.1007/s11430-010-4160-3.

_- L. Jiang, T. Zhang, B. Xu, and S. Han, 2014: Status and plans of CMA Land Data Assimilation System (CLDAS) Project. Abstracts, EGU General Assembly Conf., Vienna, Austria, European Geosciences Union, Vol. 16, EGU2014-5671, http:// meetingorganizer.copernicus.org/EGU2014/EGU2014-5671.pdf.

Shi, Y., X. Gao, J. Wu, and F. Giorgi, 2010: Simulating future climate changes over North China with a high resolution regional climate model (in Chinese). J. Appl. Meteor. Sci., 21, 580-589.

— , G. Wang, and X. Gao, 2018a: Role of resolution in regional climate change projections over China. Climate Dyn., 51, 2375-2396, https://doi.org/10.1007/s00382-017-4018-x.

_ D.-F. Zhang, Y. Xu, and B.-T. Zhou, 2018b: Changes of heating and cooling degree days over China in response to global warming of $1.5^{\circ} \mathrm{C}, 2^{\circ} \mathrm{C}, 3^{\circ} \mathrm{C}$ and $4^{\circ} \mathrm{C}$. Adv. Climate Change Res., 9, 192-200, https://doi.org/10.1016/j.accre.2018.06.003.

—, Z. Han, Y. Xu, B. Zhou, and J. Wu, 2019: Future changes of climate extremes in Xiong'an and Jing-Jin-Ji district based on high resolution $(6.25 \mathrm{~km})$ combined statistical and dynamical downscaling datasets (in Chinese). Climate Change Research, 15, 140-149.

Taylor, K. E., 2001: Summarizing multiple aspects of model performance in a single diagram. J. Geophys. Res., 106, 7183-7192, https://doi.org/10.1029/2000JD900719.

— R. J. Stouffer, and G. A. Meehl, 2012: An overview of CMIP5 and the experiment design. Bull. Amer. Meteor. Soc., 93, 485498, https://doi.org/10.1175/BAMS-D-11-00094.1.

Tong, Y., X. Gao, Z. Han, and Y. Xu, 2017: Bias correction of daily precipitation simulated by RegCM4 model over China (in Chinese). Chin. J. Atmos. Sci., 41, 1156-1166.
Vrac, M., and P. Friederichs, 2015: Multivariate-intervariable, spatial, and temporal—bias correction. J. Climate, 28, 218-237, https://doi.org/10.1175/JCLI-D-14-00059.1.

Wang, L., and W. Chen, 2014: Equiratio cumulative distribution function matching as an improvement to the equidistant approach in bias correction of precipitation. Atmos. Sci. Lett., 15, 1-6, https://doi.org/10.1002/asl2.454.

Wang, X., G. Huang, Q. Lin, X. Nie, and J. Liu, 2015: High-resolution temperature and precipitation projections over Ontario, Canada: A coupled dynamical-statistical approach. Quart. J. Roy. Meteor. Soc., 141, 1137-1146, https://doi.org/10.1002/qj.2421.

$\mathrm{Wu}$, J., and X. Gao, 2013: A gridded daily observation dataset over China region and comparison with the other datasets (in Chinese). Chin. J. Geophys., 56, 1102-1111.

Wu, J., X. Gao, and Y. Xu, 2018: Climate change projection over Xiong'an District and its adjacent areas: An ensemble of RegCM4 simulations (in Chinese). Chin. J. Atmos. Sci., 42, 696-705.

Xie, Y., S. Koch, J. McGinley, S. Albers, P. E. Bieringer, M. Wolfson, and M. Chan, 2011: A space-time multiscale analysis system: A sequential variational analysis approach. Mon. Wea. Rev., 139, 1224-1240, https://doi.org/10.1175/2010MWR3338.1.

Xu, Y., X. Gao, Y. Shen, C. Xu, Y. Shi, and F. Giorgi, 2009: A daily temperature dataset over China and its application in validating a RCM simulation. Adv. Atmos. Sci., 26, 763-772, https://doi.org/ 10.1007/s00376-009-9029-z.

Yang, F., and Coauthors, 2017: Evaluation of multiple forcing data sets for precipitation and shortwave radiation over major land areas of China. Hydrol. Earth Syst. Sci., 21, 5805-5821, https:// doi.org/10.5194/hess-21-5805-2017.

Zhang, D., Z. Han, and Y. Shi, 2017: Comparison of climate projections between driving CSIRO-Mk3.6.0 and downscaling simulation of RegCM4.4 over China. Adv. Climate Change Res., 8, 245-255, https://doi.org/10.1016/j.accre.2017.10.001.

Zhang, X., and Coauthors, 2011: Indices for monitoring changes in extremes based on daily temperature and precipitation data. Wiley Interdiscip. Rev.: Climate Change, 2, 851-870, https:// doi.org/10.1002/wcc.147.

Zhang, Y., G. Huang, X. Wang, and Z. Liu, 2017: Observed changes in temperature extremes for the Beijing-Tianjin-Hebei region of China. Meteor. Appl., 24, 74-83, https://doi.org/10.1002/met.1606.

Zhou, B., Z. Wang, Y. Shi, Y. Xu, and Z. Han, 2018: Historical and future changes of snowfall events in China under a warming background. J. Climate, 31, 5873-5889, https://doi.org/10.1175/ JCLI-D-17-0428.1.

Zhou, T., F. Song, R. Lin, X. Chen, and X. Chen, 2013: The 2012 North China floods: Explaining an extreme rainfall event in the context of a long-term drying tendency [in "Explaining Extreme Events of 2012 from a Climate Perspective"']. Bull. Amer. Meteor. Soc., 94 (8), S49-S51.

Zhou, X., G. Huang, X. Wang, Y. Fan, and G. Cheng, 2018: A coupled dynamical-copula downscaling approach for temperature projections over the Canadian Prairies. Climate Dyn., 51, 2413-2431, https://doi.org/10.1007/s00382-017-4020-3.

Zou, L., and T. Zhou, 2017: Dynamical downscaling of East Asian winter monsoon changes with a regional ocean-atmosphere coupled model. Quart. J. Roy. Meteor. Soc., 143, 2245-2259, https://doi.org/10.1002/qj.3082.

, — , and D. Peng, 2016: Dynamical downscaling of historical climate over CORDEX East Asia domain: A comparison of regional ocean-atmosphere coupled model to stand-alone RCM simulations. J. Geophys. Res., 121, 1442-1458, https:// doi.org/10.1002/2015JD023912. 